points which refer to numbered stakes found at intervals along the route, which is marked out by arrows and signs. There may be displays giving further information about the important features of the environment. At Gibraltar Point Local Nature Reserve, in Lincolnshire, there is an information centre where voluntary wardens answer questions at the weekends.

At Alvecote Pools the National Coal Board has leased a disused Methodist chapel to the West Midlands Trust for Nature, and this has been equipped as a day centre, supervised by a committee of local teachers. It is used regularly by about twenty-five schools in the area. Nature trails are clearly very valuable as a supplement to biology lessons. The handbook points out that, although the trails are chiefly a teaching aid for younger children, they can help to illustrate and clarify examination syllabuses such as advanced level botany. Plant identification and taxonomy can certainly be made more real, but whether they can be taught painlessly, as the handbook claims, is less certain.

\section{A Catalogue of Earthquakes}

The International Seismological Centre in Edinburgh is beginning to fulfil what it sees as its main function, the publication of a regional catalogue of earthquakes. The centre, formed in 1963, last year issued its first regional catalogue, which listed earthquakes for the first six months of 1964. The catalogue is based on readings from a global network of 612 stations, and lists nearly 5,000 events thought to be earthquakes, arranged according to the geographical region in which they occurred. In addition, the catalogue contains details of 186 known or probable explosions, data which can be useful for the calibration of seismographs.

Computer processing of the raw data is essential for cataloguing work of this kind, but computer programmes are remarkably prone to teething troubles, and these seem to be the main reason for the $3 \frac{1}{2}$ year delay in publication. Some time lag is inevitable, it seems, because of the inaccessibility of many earthquake recording stations, and the time the data take to reach Edinburgh. Because the catalogue is intended to be a final record, replacing preliminary results published only months after the events, data from remote stations, some in the Antarctic, are included.

The director of the centre, Dr P. L. Willmore, is hoping to cut down the delay in publication to two years or eighteen months, now that the initial difficulties have been ironed out. Once the influx of data is under control and the catalogue brought up to date, the ISC expects to find time to analyse records from before 1964 and to produce catalogues of earthquakes occurring in the $1950 \mathrm{~s}$.

The most rapid publication of preliminary seismic observations and determinations of the epicentre of earthquakes is the province of the United States Coast and Geodetic Survey. These reports are especially useful to relief expeditions dispatched to assist at earthquake disasters where local lines of communication have been destroyed. In such cases, the times and locations at which shocks occurred can be invaluable.

On the other hand, catalogues like that produced by the International Seismological Centre find their main application in long-term statistical investigations of earthquakes. Designers of large-scale structures which are especially prone to earthquakes-dams and tall office blocks, for example-like to know how susceptible the area they are building in is to earthquakes. Here the regional catalogue of earthquakes will help.

\section{Skopje Earthquake}

AFTER the earthquake in Skopje on July 26, 1963, the government of Yugoslavia decided to investigate the causes and effects of the earthquake damage, so that the city could be rebuilt with better resistance to the stresses of any future earthquake. As well as calling in Yugoslavian scientists and engineers, the government sent a request to UNESCO for experts to advise them. The findings of these four investigators have now been published (UNESCO, 51s.).

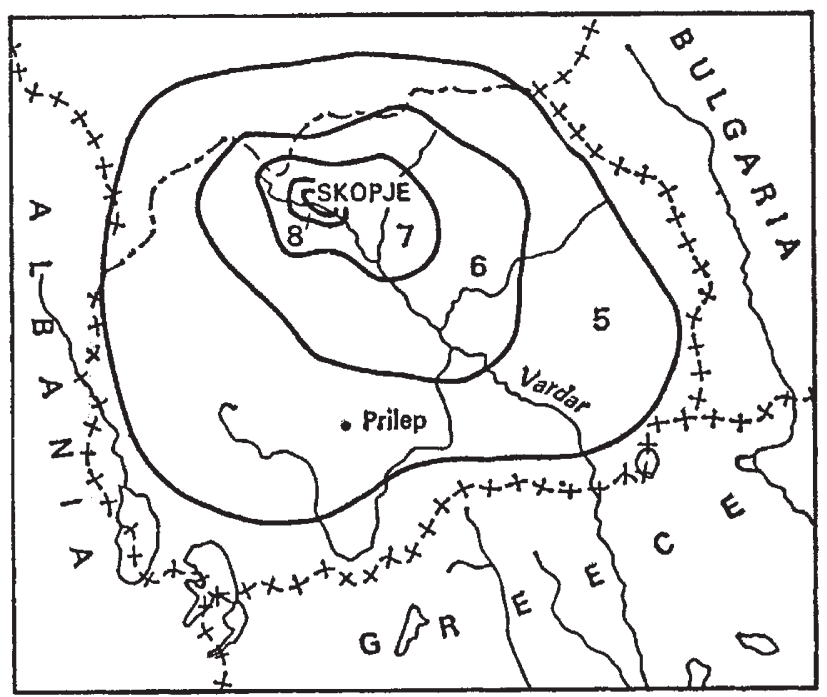

Distribution of observed intensities for earthquake on July 26, 1963 (compiled by D. Hadzievski and A. Zátopek).

Mr J. Despeyroux, chief engineer of SOCOTEC in Paris, reported on building problems and Dr N. N. Ambrayseys of Imperial College produced an engineer. ing seismology study of the earthquake. It was concluded that there would be no point in moving the city completely, but if new building developments are spread out around the city the risk will be minimized. In replanning the old city wide streets can be included to give good access to the centre. Special building codes for earthquake resistant structures are advisable, and controlled quality of structural materials, about which builders should be informed, would increase the safety of permanent buildings. Thirty per cent of the most important buildings in the city were left intact or were not irreparably damaged, those which were properly designed and constructed being the best survivors. Regulation of the River Vardar is important because it affects the seismic quality of the ground. Earthquake engineering and seismology are different, although related, subjects, and the former is neglected. Dr Ambrayseys suggests that a school should be set up in Skopje to train engineers and architects to postgraduate level in earthquake engineering, geotectonics 